\title{
Contribution of Family-Based Substance Abuse Prevention Program to Attitude and Self-efficacy of Mothers Trained by Mental Health Facilitators
}

\author{
Eilnaz Khoshzaban ${ }^{1} \&$ Hossein $_{\text {Matlabi }}{ }^{1}$ \\ ${ }^{1}$ School of Health Sciences, Tabriz University of Medical Sciences, Tabriz, Iran \\ Correspondence: Hossein Matlabi, School of Heath Sciences, Tabriz University of Medical Sciences, Attare \\ Neishabouri St, Tabriz 5165665811, Iran. Tel: 98-914-100-8927. E-mail: matlabih@tbzmed.ac.ir
}

Received: December 22, 2015 Accepted: March 12, 2016 Online Published: March 31, 2016

doi:10.5539/gjhs.v8n11p217

URL: http://dx.doi.org/10.5539/gjhs.v8n11p217

\begin{abstract}
Family plays a key role in the prevention and intervention of drug abuse among children and teenagers. Information about drugs provides parents with the exact knowledge on how to demonstrate attitudes and healthy behaviours. Therefore, the present study tried to investigate the effect of preventive and interventional trainings on self-efficacy and attitudes of mothers covered by mental health facilitators (MHFs) in this regard. This interventional study used case and control groups/pretest-posttest design. Based on the inclusion criteria, randomized sampling, and sample size formulation, 150 qualified mothers were recruited. Eligible participants were randomly divided into two intervention and control groups. A researcher-designed and self-administered questionnaire was used to gather the required data. Six instructive, communicative oral sessions and individual interviews were held by the facilitators for case group members. After two months, attitudes and self-efficacy of the mothers toward drug abuse issues were measured again by the same questionnaire. The results showed that the difference in intervention and control group was significant in terms of increasing self-efficacy and modifying attitudes $(\mathrm{p}<0.001)$. Furthermore, the case group members reported less misconceptions, stigma, and ignorance toward those suffering from addiction.
\end{abstract}

Keywords: family-based programs, mental health facilitators, drug abuse, self-efficacy

\section{Introduction}

As "substance abuse" is a "family illness" related to lifestyle; effective family reinforcement prevention programs should be included in all the activities of drug abuse issues (Kumpfer, Alvarado \& Whiteside, 2003). Studies have shown that drug abuse is more common among the adolescents. Moreover, the rate of drug distribution is dramatically increasing in these age groups (Alahverdipour et al., 2006).

Family plays an important and influential role in the lives of the youth and longitudinal research shows that improving parenting skills may reduce the youth's substance use (Allen et al., 2012). In this regard, researchers have claimed proper parental guides and trainings could influence prevention of the risk factors. Parents can act quickly and calmly by being aware of the symptoms of substance abuse and help their children by early detection and selection of positive approaches (Malley et al., 1988; Hermida et al., 2003).

Family bonding is the cornerstone of the relationship between parents and children. Bonding can be strengthened through skills training regarding the supportiveness of children, the interaction of child-parent, and parental involvement (Kosterman et al., 1997). Training about drugs and providing information by parents are focused on what children learn about the harmful effects of drugs and create opportunities to hold family discussions about drug abuse and other illegal substances (Bauman et al., 2001). Such family-based interventions will result in positive changes in parent's behaviours and consequently decrease the following drug abuse risks for all the people (Spoth et al., 2002).

Parents' self-efficacy refers to their assessment of their own ability to play parenting role and is an important cognitive structure regarding their functionality (Mash \& Johnston, 1990; Kuhn \& Carte, 2006). In order to feel the sense of self-efficacy, they need to be informed and knowledgeable about effective ways of treating their children. They should trust their own abilities and be sure that their performance will have a positive impact on children (Coleman \& Karraker, 1997; Teti \& Gelfand, 1991). Parents' education programs may improve their 
adjustment mechanism, allowing them to more easily accept the situation of their children and to have a more effective role in their development (Keen et al., 2007; Shields, 2001).

Considering the fact that one of the main personal vulnerabilities is the lack of general knowledge and proper attitude, this study was carried out to evaluate the contribution of the family-based substance abuse prevention program to attitudes and self-efficacy of mothers covered by mental health facilitators.

\section{Methodology}

\subsection{Ethics Statement}

This study was approved by Board of Ethics Committee, Tabriz University of Medical Sciences (approval number: 5/4/5086-15/09/2013). Informed consent was obtained from the participants included in the research. All procedures performed in study were in accordance with the ethical standards of the institutional and national research committee.

\subsection{Participants and Procedure}

A pre-test/post-test with a control group was carried out in this study. Convenient sampling was used to recruit seven mental health facilitators from Marand, East Azerbaijan-Iran. In order to empower the facilitators, four group-discussion sessions were held in which women shared their experiences about self-efficacy, drug abuse, health promotion strategies, and life skills. In order to assess requirements and produce educational contents for mothers, comments of drug prevention experts, MHFs perspectives, and parents were analysed.

The ideas of drug prevention experts and MHFs about mothers' required skills regarding children's drug abuse prevention were scrutinized by Nominal Group Technique. At the next stage and based on inclusion criteria and randomised sampling, 150 qualified women were entered into the study. Then the samples were randomly divided into two control and intervention groups. Mothers with children aged 12-18 and with no addicted family members were included. Mothers' self-efficacy and attitudes among two groups of respondents was assessed by researcher's designed questionnaire and by individual interviews.

Six educational and communicative oral sessions were held by facilitators for the case group members. Training sessions included topics such as the importance of children monitoring, the importance of and how to create rules in the family, increasing the skills necessary to create strong family ties, manner appropriate parenting, types of drugs, and signs of drug abuse by children. Furthermore, during the learning sessions a pamphlet was distributed and its contents shared properly. Finally, after two months the self-efficacy and attitudes of both groups was examined by the same questionnaire.

\subsection{Instrument}

A researcher's designed and self-administered questionnaire consisting two parts was used to gather the required data. The first part of the questionnaire included socio-demographic items including age, gender, marital status, level of educational, place of birth, employment status, smoking habits in family, drug use in family and relatives. With regard to self-efficacy, 12 questions with three options including agree, disagree, and no opinion were asked and total score of the questions was in the range of 12-36. Moreover, the applied questionnaires also included eight questions assessing attitude toward drug abuse issues on a Likert scale of 5 points.

\subsection{Validity}

Two factors of content validity ratio (CVR) and content validity index (CVI) were assessed and approved by a panel of ten experts in health psychology, health education and promotion, clinical psychology, social worker, and educational planning. Eight experts in the field offered their opinions, and their suggestions in this regard were applied. Experts' responses were calculated based on the CVR estimation formula and the results obtained from the decision-making table of content validity ratio. All the questions had the perfect agreement $(\mathrm{CVR}=+1)$.

Moreover, to determine the content validity index, the experts separately studied the three criteria of simplicity, relevance, and clarity of questions. In this regard, the CVI was calculated using the total scores for each question according to the total number of experts on the basis of CVI. Then, all the questions were in the range of $0.75-1$ which gained of a high content validity.

\subsection{Reliability}

The questionnaire was evaluated among 50 eligible participants before intervention. Reliability of the final draft was accepted using Cronbach's alpha coefficient (attitude items: $\alpha=0.79$ and self-efficacy questions: $\alpha=0.67$ ). 


\section{Results}

The mean ages for the intervention group (IG) and control group (CG) were 43.61 \pm 9.63 and $44.61 \pm 7.14$ respectively. The majority of the respondents were housewives. About $5.3 \%$ of the mothers in IG and $1.3 \%$ in CG reported smoking experiences in their lifetime. Moreover, $68 \%$ of IG and $57.3 \%$ of CG declared that they were aware of addiction experiences like smoking among their children. Nearly half of the mothers in the IG and one-third in the CG had talked about addictive substances with their children. Only $20 \%$ of IG and $26.7 \%$ of CG had attended drug abuse prevention programs. Most of the participants had obtained information about drug abuse from the television. The results indicated that there were no significant differences among intervention and control group members in terms of demographic variables. A further socio-demographic characteristic of the mothers is presented in Table 1.

Table 1. The distribution of socio-demographic characteristics of the participants $(n=150)$

\begin{tabular}{lll}
\hline Variables & $\begin{array}{l}\text { Intervention group } \\
(\mathbf{n = 7 5 )} \mathbf{n}(\mathbf{\%})\end{array}$ & $\begin{array}{l}\text { Control group } \\
(\mathbf{n = 7 5 )} \mathbf{n} \text { (\%) }\end{array}$ \\
\hline Age & & \\
$30-49$ & $58(74.4)$ & $56(76)$ \\
$50-69$ & $17(25.6)$ & $19(24)$ \\
Job & & \\
Housewife & $66(88)$ & $72(96)$ \\
Employed & $9(12)$ & $3(4)$ \\
Education & & \\
Illiterate & $9(12)$ & $6(8)$ \\
Primary school & $2(2.7)$ & $6(8)$ \\
High school & $26(34.7)$ & $30(40)$ \\
Diploma & $28(37.3)$ & $28(37.3)$ \\
Undergraduate & $3(4)$ & $3(4)$ \\
Postgraduate & $7(9.3)$ & $2(2.7)$ \\
Living with wife or husband & $70(93.3)$ & $64(85.3)$ \\
Smoking experiences & $4(5.3)$ & $1(1.3)$ \\
Husband smoking & $32(42.7)$ & $26(34.7)$ \\
Children smoking & $51(68)$ & $43(57.3)$ \\
Family history of substance abuse & $11(14.7)$ & $13(17.3)$ \\
Drug abuse prevention programs & $15(20)$ & $20(26.7)$ \\
\hline & & \\
\hline & & \\
& &
\end{tabular}

As can be seen in Table 2 and 3, the mean scores of the questions related to attitude and self-efficacy between the two groups did not show any significant difference before the intervention; however, significant differences were observed after the program. Furthermore, the paired t-test revealed that there was no significant difference in the values of main variables in the control group in the pre-test and post-test steps. However, the findings of the intervention group showed an increase in the mothers' attitude and self-efficacy and a decrease in positive attitude toward drugs after attending the training program by MHFs. Moreover, the differences between the pre-test and post-test were significant meaningful in this group. 
Table 2. Comparing the mean and standard deviation of main variables among both groups $(\mathrm{n}=150)^{*}$

\begin{tabular}{|c|c|c|c|c|c|c|c|c|}
\hline \multirow{3}{*}{ Variables } & \multicolumn{2}{|c|}{ Before intervention } & \multirow{3}{*}{ ES } & \multirow{3}{*}{ p.value } & \multicolumn{2}{|c|}{ After intervention } & \multirow{3}{*}{ ES } & \multirow{3}{*}{ p.value } \\
\hline & \multirow{2}{*}{$\begin{array}{l}\text { Case } \\
\text { Mean; SD }\end{array}$} & \multirow{2}{*}{$\begin{array}{l}\text { Control } \\
\text { Mean; SD }\end{array}$} & & & \multirow{2}{*}{$\begin{array}{l}\text { Case } \\
\text { Mean; SD }\end{array}$} & \multirow{2}{*}{$\begin{array}{l}\text { Control } \\
\text { Mean; SD }\end{array}$} & & \\
\hline & & & & & & & & \\
\hline Attitude & $17.16 ; 6.73$ & $14.81 ; 7.20$ & 15.86 & 0.105 & $10.67 ; 3.55$ & $13.29 ; 4.13$ & -19.71 & $0.001<$ \\
\hline Self-efficacy & $27.32 ; 4.73$ & $27.89 ; 4.51$ & -2.04 & 0.449 & $33.04 ; 2.97$ & $27.69 ; 4.64$ & 19.32 & $0.001<$ \\
\hline
\end{tabular}

*(Independent samples $t$-test).

Table 3. Comparing the pre-test and post-test scores of variables in both groups $(\mathrm{n}=150)^{*}$

\begin{tabular}{|c|c|c|c|c|c|c|c|c|}
\hline \multirow{3}{*}{ Variables } & \multicolumn{2}{|l|}{ Case group } & \multirow{3}{*}{ ES } & \multirow{3}{*}{ p.value } & \multicolumn{2}{|c|}{ Control group } & \multirow{3}{*}{ ES } & \multirow{3}{*}{ p.value } \\
\hline & Pre-test & Post-test & & & Pre-test & Post-test & & \\
\hline & Mean; SD & Mean; SD & & & Mean; SD & Mean; SD & & \\
\hline Attitude & $17.16 ; 6.73$ & $10.67 ; 3.55$ & -37.82 & $0.001<$ & $14.81 ; 7.20$ & $13.29 ; 4.13$ & -10.26 & 0.135 \\
\hline Self-efficacy & $27.32 ; 4.73$ & $33.04 ; 2.97$ & 20.93 & $0.001<$ & $27.89 ; 4.51$ & $27.69 ; 4.64$ & -0.71 & 0.100 \\
\hline
\end{tabular}

$*($ Paired t-test $)$

\section{Discussion and Conclusion}

The present study tried to investigate the effect of preventive and interventional trainings on self-efficacy and attitudes of mothers covered by mental health facilitators. Studies have shown that appropriate parenting skills, enforcing family policies on misuse of drugs, and training about drug abuse issues improve relationships and bond to their family members (Ashery et al., 1998). Parents influence the behavior of drug use in children's through family relations, modeling and raising the standards, and attitudes that children learn and practice to guide their behavior in new situations (Schor, 1996). This concern can be done by developing extra-familial social support and socialization for children and adolescents, resources to accomplish an activity or to undertake an enterprise and achieve desired outcome (Dumas et al., 2011).

The results of this study revealed that training skills in the field of addiction prevention could improve self-efficacy of mothers and improve negative attitudes toward drugs issues. Allen (2013) conducted a study entitled "Feasibility of a parenting program to prevent substance use among Latino youth: A community-based participatory research". Eighty-three parents with adolescents aging 10-14 years old were selected. A program was designed and held for parents to improve parenting skills and parent-youth interpersonal relations. The results showed the feasibility of this approach which may influence parenting contributors to adolescent substance use (Allen et al., 2013). Moreover, a randomized controlled study was conducted to investigate the effectiveness of online parents-based interventions for reducing the risks associated with students' alcohol consumption. The findings suggested that the parents who participated in the online intervention or action online than parents in the control group tend to talk about caring strategies related to drinking alcohol, stop or limit alcohol consumption.Web-based universal interventions would be an efficient and effective component of a college's overall prevention strategy to reduce risks associated with student alcohol consumption (Donovan et al., 2012).

A further study conducted among Spanish parents using a wide range of approaches including drugs awareness events, life courses with teenagers, and youth development interventions to increase self-esteem, peer- education practices, voluntary friendship schemes, and mutual learning of child-parent (Velleman et al., 2000). It was specified that empowering very poor or marginalized parents who do not pay attention to school events or do not participate properly in discussion opportunities was difficult. Furthermore, the lack of time, money, attention to child and fear of being labeled by others were reported the main barriers. Also, it was indicated that engaging fathers in projects was a very problematic task, though there were many evidences that boys are more inclined to interact with their fathers and are more affected by them concerning drugs. Finally, long-term support for troubled families was recommended.

The present study revealed several positive effects on mothers who comprised a more detailed knowledge and 
more realistic understanding of the drug prevention capacities, greater confidence in communicating with children, positive impact on them and overcoming the drug-related behaviors. It also concluded that the main task of these programs would improve parenting skills including strengthen confidence, communication skills and general understanding of young people during the more compact and short periods. Kampfer et al. provided evidence for the effectiveness of some types of family- based intervention approaches that include home-based family support, behavioral parent training, family skills training, family education and family therapy. These researchers stated that family- based intervention approaches have the effect sizes 2-9 times higher than approaches that focus only on children and argued that "prevention programs should include all of drug abuse preventive activities by emphasizing on child reinforcement". The main component of family- based prevention programs reported as appropriate and specific interactive forms which the ability to reach them always looks difficult at first (Kumpfer et al., 2003). There were some evidences that the combination of family and child-focused approaches can also be more effective. The most famous example is strengthening families program (SFP) which has been successfully evaluated and subsequently repeated in different situations with different groups (Vellman et al., 2005).

\section{Acknowledgements}

This study was financed by a grant from the Tabriz University of Medical Sciences (grant no. 5/53/2914-2013/09/19). We would like to appreciate Dr. Shaghaghi for his useful advice, all those mental health facilitators, participants, deputy of social issues prevention of state welfare organization of East- Azerbaijan, Mr Shabani, and his colleagues. We also thank the staffs of Tabriz University of Medical Sciences and its deputy for research and technology.

\section{Conflict of Interest}

The authors declare that there is no conflict of interests regarding the publication of this paper.

\section{References}

Alahverdipour, H., Heydarnia, A., Kazemnezhad, A., Wyt, K., Shafee, F., \& Azad Fallah, P. (2006). Application of fear stimulating theory on the prevention of Drug Abuse among High School boys in Tehran. Journal of Hamedan University of Medical Sciences, 13(3), 43-50. Retrieved from http://fa.journals.sid.ir/ViewPaper.aspx?id=53976

Allen, M. L., Garcia-Huidobro, D., Hurtado, G. A., Allen, R., Davey, C. S., Forster, J. L., ... Svetaz, M. V. (2012). Immigrant family skills-building to prevent tobacco use in Latino youth: Study protocol for a community-based participatory randomized controlled trial. Trials, 19(3), 242. http://dx.doi.org/10.1186/1745-6215-13-242

Allen, M. L., Hurtado, G. A., Yon, K. J., Okuyemi, K. S., Davey, C. S., Marczak, M. S., ... Svetaz, V. M. (2013). Feasibility of a parenting program to prevent substance use among Latino youth: A community-based participatory research study. American Journal of Health Promotion, 27(4), 240-4. http://dx.doi.org/10.4278/ajhp.110204-ARB-52

Ashery, R. S., Robertson, E. B., \& Kumpfer, K. L. (1998). Drug Abuse Prevention Through Family Interventions. NIDA Research Monograph, 177. Retrieved from https://archives.drugabuse.gov/pdf/monographs/ monograph177/monograph177.pdf

Bauman, K. E., Foshee, V. A., Ennett, S. T., Pemberton, M., Hicks, K. A., King, T. S., \& Koch, G. G. (2001). The influence of a family program on adolescent tobacco and alcohol. American Journal of Public Health, 91(4), 604-10. http://dx.doi.org/10.2105/AJPH.91.4.604

Coleman, P. K., \& Karraker, K. H. (1997). Self-efficacy and parenting quality: Findings and future applications. Developmental Review, 18(1), 47-85. http://dx.doi.org/10.1006/drev.1997.0448

Dumas, E., Arriaga, X., \& Begle, A. (2011). Child and parental outcomes of a group parenting intervention for Latino families: A pilot study of the CANNE program. Cultur Divers Ethnic Minor Psychol, 17(1), 107-115. http://dx.doi.org/10.1037/a0021972

Donovan, E., Wood, M., Frayjo, K., Black, R. A., \& Surette, D. A. (2012). A randomized, controlled trial to test the efficacy of an online, parent-based intervention for reducing the risks associated with college-student alcohol use. Addictive Behaviors, 37(1), 25-35. http://dx.doi.org/10.1016/j.addbeh.2011.09.007

Hermida, J. F., Scades villa, R. S., Seco, G. V., \& Perez, J. E. (2003). Evaluation of what parents know about their children's drug use and how they perceive the most common family risk factors. Journal of Drug Education, 33(3), 337-53. http://dx.doi.org/10.2190/60R8-W31R-FT0H-J1TF 
Keen, D., Rodger, S., Doussin, K., \& Braithwiate, M. (2007). A pilot study of the effect of a social pragmatic intervention on the communication and symbolic play of children with autism. Autism, 11(1), 63-71. http://dx.doi.org/10.1177/1362361307070901

Kosterman, R., Hawkins, J. D., Spoth, R., Haggerty, K. P., \& Zhu, K. (1997). Effects of a preventive parent-training intervention on observed family interactions: Proximal outcomes from 'Preparing for the Drug Free Years'. Journal of Community Psychology, 25(4), 337-352. http://dx.doi.org/10.1002/(SICI)1520-6629(199707)25:4<337::AID-JCOP3>3.0.CO;2-R

Kumpfer, K. L., Alvarado, R., \& Whiteside, H. O. (2003). Family-based interventions for substance use and misuse prevention. Substance Use \& Misuse, 38(11-13), 1759-87. http://dx.doi.org/10.1081/JA-120024240

Kuhn, J. C., \& Carter, A. S. (2006). Maternal self-efficacy and associated parenting cognitions among mothers of children with autism. American Journal of Orthopsychiatry, 76(4), 564-75. http://dx.doi.org/10.1037/0002-9432.76.4.564

Malley, P. M., Bachman, J. G., \& Johnston, L. D. (1988). Period, age and cohort effects on substance use among young Americans: A decade of change, 1976-1986. American Journal of Public Health, 78(10), 1315-21. http://dx.doi.org/10.2105/AJPH.78.10.1315

Mash, E., \& Johnston, C. (1990). Determinations of parenting stress: Illustrations from families of hyperactive children and families of physically abused children. Journal of Clinical Child \& Adolescent PsychologyPsychol, 19(4), 313-28. http://dx.doi.org/10.1207/s15374424jccp1904_3

Schor, E. L. (1996). Adolescent alcohol use: Social determinants and the case for early family-centred prevention. Family-focused prevention of adolescent drinking. The bulletin of the New York Academy of Medicine, 73(2), 335-56. Retrieved from http://www.ncbi.nlm.nih.gov/pubmed/8982525

Shields, J. (2001). The NAS Early bird programme: Partnership with parents in early intervention. Autism, 5(1), 49-56. http://dx.doi.org/10.1177/1362361301005001005

Spoth, R. L., Redmond, D., Trudeau, L., \& Shin, C. (2002). Longitudinal substance initiation outcomes for a universal preventive intervention combining family and school programs. Psychology of Addictive Behaviors, 16(2), 129 - 34. http://dx.doi.org/10.1037/0893-164X.16.2.129

Teti, D., \& Gelfand, D. (1991). Behavioural competence among mothers of infants in the first year: The meditational role of maternal self-efficacy. Child Development, 62(5), 918-29. http://dx.doi.org/10.2307/1131143

Velleman, R., Mistral, W., \& Sanderling, L. (2000). Taking the Message Home: Involving Parents in Drugs Prevention. London; Home Office. Drugs Prevention Advisory Service. Retrieved from https://www.ncjrs.gov/App/publications/abstract.aspx?ID=186040

Vellman, R., Templeton, \& Copello, A. (2005). The role of the family in preventing and intervening with substance use and misuse: a comprehensive review of family interventions, with a focus on young people. Drug and Alcohol Review, 24, 93-109. http://dx.doi.org/10.1080/09595230500167478

\section{Copyrights}

Copyright for this article is retained by the author(s), with first publication rights granted to the journal.

This is an open-access article distributed under the terms and conditions of the Creative Commons Attribution license (http://creativecommons.org/licenses/by/3.0/). 